\title{
Green Synthesis of Mesoporous Fe-SBA-15 with Well-Isolated Iron Sites
}

\author{
Hongchuan Xin ${ }^{1, *}$, Yuan Fang ${ }^{1,2}$, and Xuebing $\mathrm{Li}^{1}$ \\ ${ }^{1}$ Key Laboratory of Biofuels, Qingdao Institute of Bioenergy and Bioprocess Technology, \\ Chinese Academy of Sciences, 189 Songling Road, Qingdao 266101, China \\ ${ }^{2}$ School of Petrochemical Engineering, Changzhou University, Changzhou 213164, China
}

\section{ABSTRACT}

The ordered iron-substituted mesoporous silicas (Fe-SBA-15) have been hydrothermally synthesized under environmentally friendly conditions. In the presence of tetramethoxysilane (TMOS), triblock copolymer surfactant P123 and iron nitrate, highly ordered Fe-SBA-15 can be obtained. The results of X-ray diffraction (XRD), nitrogen sorption and transmission electron microscopy (TEM) indicate the easy formation of highly ordered hexagonal structures without addition of external acid. The mild template-removal route based on Fenton's mechanism through $\mathrm{H}_{2} \mathrm{O}_{2}$ oxidation is employed, as compared with conventional high-temperature calcination. The $\mathrm{H}_{2} \mathrm{O}_{2}$ oxidation is proved to be a better method to obtain desirable iron sites, as evidenced by UV-Vis spectroscopy. The current synthesis system provides a green route for the synthesis of Fe-SBA-15 with wellisolated iron species.

KEYWORDS: Mesoporous, Catalyst, Fe-SBA-15, Fenton, Green.

\section{INTRODUCTION}

Ordered mesoporous silicas with controllable structures and systematic tailoring pore architecture have attracted much attention in past decades, due to their potential applications in various fields, such as adsorption, catalysis and drug delivery, sensors, photonics, etc. ${ }^{1}$ Compared with the microporous zeolites, which present severe mass transfer limitations when large reactant molecules are involved, especially in liquid-phase systems for the synthesis of fine chemicals, ${ }^{2,3}$ the mesoporous catalysts demonstrate promising potential in these applications. ${ }^{4}$ Many reviews have summarized the catalytic applications of mesoporous silica $^{5-7}$ or mesoporous zeolite ${ }^{8}$ as catalyst supports. There are many strategies for the design and synthesis of mesoporous catalysts, owing to the uniform pore size and extremely high surface area. ${ }^{9}$ The synthesis procedures include the substitution of elements in the framework, impregnation of active components, and immobilization of active species with pre-determined structure, which can create well-isolated sites with specific properties. ${ }^{10}$ Among these, metal-substituted mesoporous silicas are of great interest because these metal-functionalized materials may find use in catalysis, such as acid catalysis, base catalysis, redox catalysis, alkylation, etc.

\footnotetext{
*Author to whom correspondence should be addressed.

Email: xinhc@ qibebt.ac.cn

Received: 18 February 2014

Accepted: 7 March 2014
}

Iron-containing porous catalysts are especially interesting for acid-catalyzed reactions and selective oxidation of hydrocarbons. ${ }^{10,11}$ Compared with microporous counterpart Fe-ZSM-5 catalyst, ${ }^{11-13}$ the mesoporous Fesilica catalysts show superior catalytic performance in various reactions, especially in those reaction involving bulky molecules. For the synthesis of Fe-containing mesoporous silicas, one may employ post-synthetic and directsynthetic procedures. ${ }^{10}$ For the post-synthetic one, most efforts focused on grafting specific iron clusters, ${ }^{14}$ or impregnating or ion-exchanging iron precursors ${ }^{15}$ onto the silica supports. On the contrary, the direct hydrothermal synthesis route is a more simple route, generally requiring mesopore-directing agent under acidic, ${ }^{16}$ neutral, ${ }^{17}$ or basic $^{18}$ conditions. In conventional processes, the direct synthesis will generate a large amount of liquid wastes, such as the acids or bases used in the reaction systems. Therefore, researchers worldwide keep pursuing environmentally benign procedures to manufacture these porous catalysts, since the pollution issue nowadays would be a big concern when in large scale production.

In order to make this process greener, we have investigated the synthesis of iron-containing mesoporous silicas under mild conditions. ${ }^{19-21}$ The buffer solution is taken as the effective reaction medium, ${ }^{19,20}$ and the weak acidic medium is found to facilitate the formation of high amount of well-isolated iron species, ${ }^{22}$ which are generally responsible for the selective oxidation reaction. ${ }^{19,23}$ We also studied the self-generated acidic medium as the 
reaction system for the successful fabrication of ironcontaining cage-like mesoporous silicas Fe-FDU-12. ${ }^{21}$ The iron-containing hollow silica nanospheres with uniform size have also been prepared without adding any mineral acids. These studies have provided green routes for the facile preparation of iron/mesoporous silicas.

As an important member of ordered mesoporous silicas, SBA-15 has attracted more attention in the application of catalysis, due to its high thermal, hydrothermal and mechanical stability and tunable wall thickness and pore diameter. ${ }^{24-26}$ Nonionic-surfactant-templating approach (with P123, F127, etc. as the structure-directing agents) has been widely reported for the synthesis of mesoporous silicas, ${ }^{1}$ such as SBA-15 with hexagonal channels, ${ }^{26}$ however, most work employed strong acidic conditions (by adding external mineral acid, such as $\mathrm{HCl}$ or $\mathrm{H}_{2} \mathrm{SO}_{4}$ ) to ensure the formation of highly ordered meso-structure. The direct preparation of hexagonallystructured $\mathrm{Sn}(\mathrm{Zr})-\mathrm{SBA}-15$ was also reported in a selfgenerated acidic environment. ${ }^{27,28}$ Therefore, it would be a challenge to prepare highly ordered Fe-SBA-15 without addition of external acids. Moreover, strong acidic system is not favorable to incorporate transition-metal ions (such as $\mathrm{Fe}, \mathrm{Cu}$ ) due to their high solubility in such media.

Conventionally, the template removal for as-synthesized porous materials employs a calcination procedure in hightemperature oven, which may generate gaseous pollutants (such as $\mathrm{CO}_{2}, \mathrm{NO}_{x}$, etc.). It is well-know that, the $\mathrm{Fe}-\mathrm{H}_{2} \mathrm{O}_{2}$ system as an effective Fenton agent has strong oxidation ability, which is often used to dispose of wastewater. It was also reported the $\mathrm{H}_{2} \mathrm{O}_{2}$ is favorable to the remove the nonionic-surfactant P123 after the hydrothermal crystallization process and to the incorporation of the iron species into the $\mathrm{SiO}_{2}$ matrix. ${ }^{29}$

To the best of our knowledge, there are very few reports on the synthesis of Fe-substituted mesoporous silicas via direct hydrothermal route without addition of external acid. ${ }^{21,30,31}$ Herein, we report the direct synthesis of $\mathrm{Fe}$ SBA-15 in a green route, including green hydrothermal step and green template-removal step.

\section{EXPERIMENTAL DETAILS}

\subsection{Reagents}

All materials were of analytical grade and used as received without any further purification. Triblock poly(ethylene oxide)-poly(propylene oxide)-poly(ethylene oxide) copolymer Pluronic P123 $\left(\mathrm{EO}_{20} \mathrm{PO}_{70} \mathrm{EO}_{20}\right)$ were purchased from Sigma-Aldrich Company Ltd. (USA). Tetramethoxysilane (TMOS), $\mathrm{Fe}\left(\mathrm{NO}_{3}\right)_{3} \cdot 9 \mathrm{H}_{2} \mathrm{O}$, and other reagents were obtained from Shanghai Chemical Reagent. Inc., of Chinese Medicine Group.

\subsection{Synthesis}

For the synthesis of Fe-SBA-15 samples, $2.00 \mathrm{~g}$ of P123 and $0.063 \mathrm{~g}$ of $\mathrm{Fe}\left(\mathrm{NO}_{3}\right)_{3} \cdot 9 \mathrm{H}_{2} \mathrm{O}$ were dissolved in $40 \mathrm{~mL}$ of water. The solution was stirred at $40{ }^{\circ} \mathrm{C}$ for $2 \mathrm{~h} .3 .04 \mathrm{~g}$ of TMOS was added to the above surfactant solution. After stirring at $40{ }^{\circ} \mathrm{C}$ for $24 \mathrm{~h}$, the mixture was transferred into a Teflon-lined autoclave and aged at $100{ }^{\circ} \mathrm{C}$ for another 24 h. The precipitate was filtered off, rinsed repeatedly with water and dried at $100{ }^{\circ} \mathrm{C}$.

The as-synthesized sample was calcined in air at $550{ }^{\circ} \mathrm{C}$ for $10 \mathrm{~h}$ with a ramp of $1{ }^{\circ} \mathrm{C} \mathrm{min}^{-1}$. The calcined sample was denoted as Fe-SBA, where 0.8 is the mol\% of $\mathrm{Fe} / \mathrm{Si}$ in the starting solution. Alternatively, the template of the as-synthesized sample was removed by treating $1.0 \mathrm{~g}$ of the sample in $250 \mathrm{~mL}$ of $6 \% \mathrm{H}_{2} \mathrm{O}_{2}$ aqueous solution. The $\mathrm{H}_{2} \mathrm{O}_{2}$-treated sample was denoted as Fe-SBA- $\mathrm{H}_{2} \mathrm{O}_{2}$.

\subsection{Characterization}

X-ray diffraction (XRD) patterns were recorded on a Rigaku RINT D/Max-2500 powder diffraction system using $\mathrm{Cu} \mathrm{K} \alpha$ radiation of $0.15406 \mathrm{~nm}$ wavelength. The nitrogen sorption experiments were performed at $-196{ }^{\circ} \mathrm{C}$ on a Micromeritics ASAP 2020 system. Prior to the measurement, the materials were out gassed at $120{ }^{\circ} \mathrm{C}$ for at least $6 \mathrm{~h}$. The Brunauer-Emmett-Teller (BET) specific surface areas were calculated using the adsorption data in the relative pressure $\left(P / P_{0}\right)$ range of $0.05-0.25$. Pore size distributions were calculated using the Barrett-JoynerHalenda (BJH) method based on the adsorption branch. The total pore volumes were estimated from the amounts adsorbed at a relative pressure $P / P_{0}$ of 0.99 . Transmission electron microscopy (TEM) was performed using a JEOL JEM-2000EX and a FEI Tecnai $\mathrm{G}^{2}$ Spirit at an acceleration voltage of $120 \mathrm{kV}$. UV-Vis diffuse reflectance spectra were recorded on a JASCO V-550 UV-Vis spectrophotometer. The powder material was loaded into a quartz cell, and the spectra were collected in the range of 190 to $800 \mathrm{~nm}$ with $\mathrm{BaSO}_{4}$ as the reference. The elemental analysis was determined by ICP-AES after the material was dissolved in a mixture of $\mathrm{HF}$ and $\mathrm{HNO}_{3}$.

\section{RESULTS AND DISCUSSION}

The elemental analysis results of Fe-SBA- $\mathrm{H}_{2} \mathrm{O}_{2}$ and FeSBA samples are shown in Table I. It can be seen that, $\mathrm{Fe}-\mathrm{SBA}-\mathrm{H}_{2} \mathrm{O}_{2}$ contains less iron than Fe-SBA, since the $\mathrm{H}_{2} \mathrm{O}_{2}$-aided template removal process results in easy leaching of iron from SBA-15 support, which is often found

Table I. Structural parameters of Fe-SBA-15.

\begin{tabular}{lcccc}
\hline Material & $\begin{array}{c}\mathrm{Fe} \text { content } \\
(\mathrm{wt} . \%)\end{array}$ & $\begin{array}{c}S_{\mathrm{BET}}^{a} \\
\left(\mathrm{~m}^{2} / \mathrm{g}\right)\end{array}$ & $\begin{array}{c}V_{t}^{b} \\
\left(\mathrm{~cm}^{3} / \mathrm{g}\right)\end{array}$ & $\begin{array}{c}D_{\mathrm{BJH}}^{c} \\
(\mathrm{~nm})\end{array}$ \\
\hline Fe-SBA- $\mathrm{H}_{2} \mathrm{O}_{2}$ & 0.19 & 1118 & 1.58 & 9.3 \\
Fe-SBA & 0.30 & 842 & 1.14 & 7.9 \\
\hline
\end{tabular}

${ }^{a} S_{\mathrm{BET}}$ is the BET specific surface area; ${ }^{\mathrm{b}} V_{t}$ is the total pore volume determined at the relative pressure of $0.98 ;{ }^{\mathrm{c}} D_{\mathrm{BJH}}$ is $\mathrm{BJH}$ pore diameter calculated by the adsorption branches of the nitrogen sorption isotherms. 


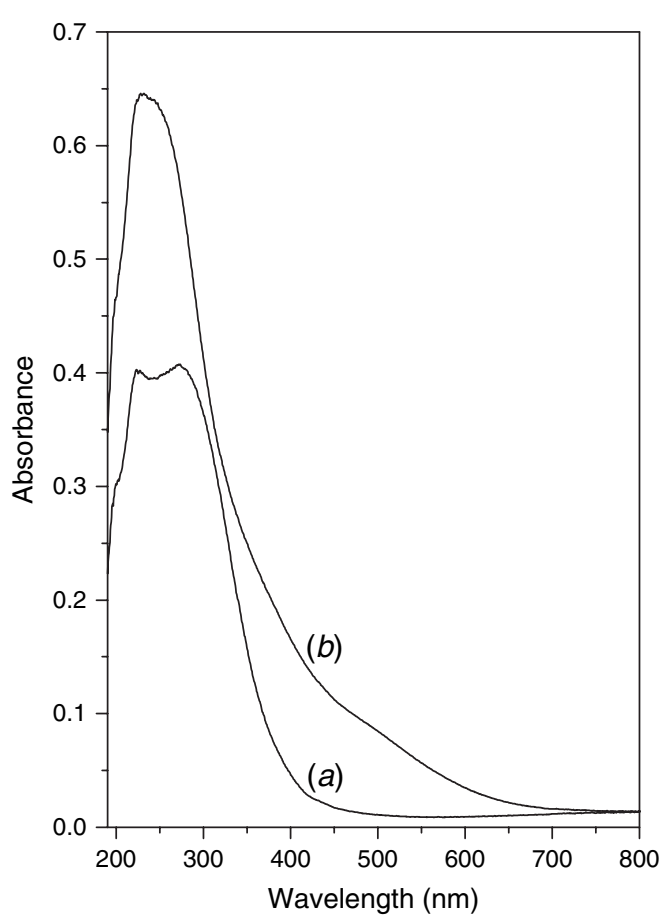

Fig. 1. UV-Vis spectra of Fe-SBA-15: (a) Fe-SBA- $\mathrm{H}_{2} \mathrm{O}_{2}$ and (b) Fe-SBA.

in the oxidation reaction catalyzed over Fe catalysts with $\mathrm{H}_{2} \mathrm{O}_{2}$ as oxidant. ${ }^{19}$

The coordination environment of iron species in $\mathrm{Fe}$ SBA-15 was characterized using UV-vis diffuse reflectance spectroscopy as displayed in Figure 1. The UV-vis spectrum of Fe-SBA- $\mathrm{H}_{2} \mathrm{O}_{2}$ mainly show a strong absorption peak centered at $274 \mathrm{~nm}$ and a shoulder peak at $225 \mathrm{~nm}$,

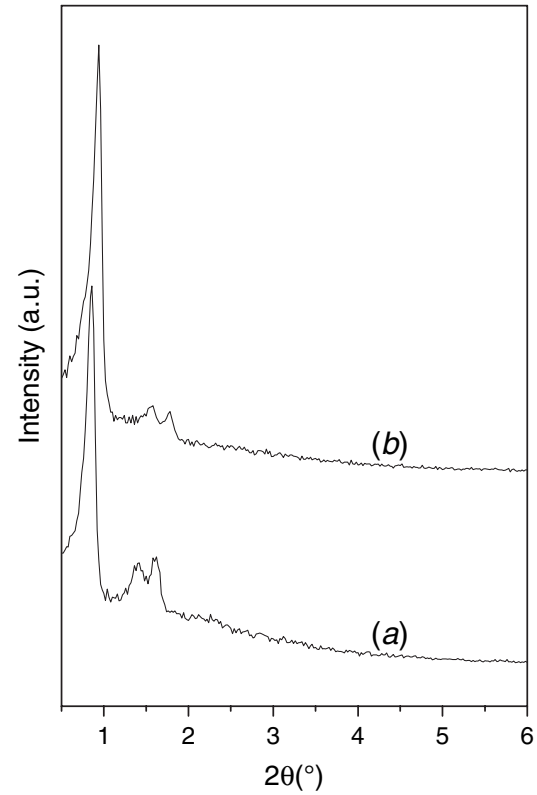

Fig. 3. XRD patterns of Fe-SBA-15: (a) Fe-SBA- $\mathrm{H}_{2} \mathrm{O}_{2}$ and (b) Fe-SBA.

which can be assigned to the ligand-to-metal charge transfer band of isolated tetrahedrally coordinated $\mathrm{Fe}^{3+}$. No significant absorption peak is observed above $400 \mathrm{~nm}$, suggesting that the samples are free of iron oxide oligomers or ferric oxide species. ${ }^{19}$ The UV-vis spectrum of Fe-SBA mainly exhibits a weak adsorption band above $400 \mathrm{~nm}$ in addition to the peaks at 230 and $253 \mathrm{~nm}$, indicating the presence of extra-framework iron oligomer or aggregated iron oxide clusters. It is obvious that more uniform and isolated iron species can be obtained in the $\mathrm{H}_{2} \mathrm{O}_{2}$-treated

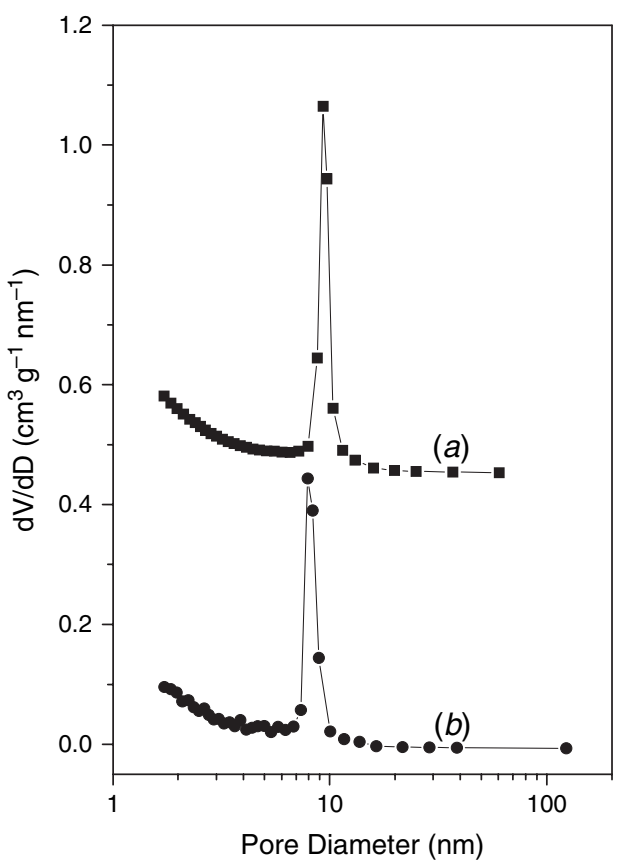

Fig. 2. Nitrogen sorption isotherms (left) and BJH mesopore size distributions (right) of Fe-SBA-15: (a) Fe-SBA- $\mathrm{H}_{2} \mathrm{O}_{2}$ and (b) Fe-SBA. 


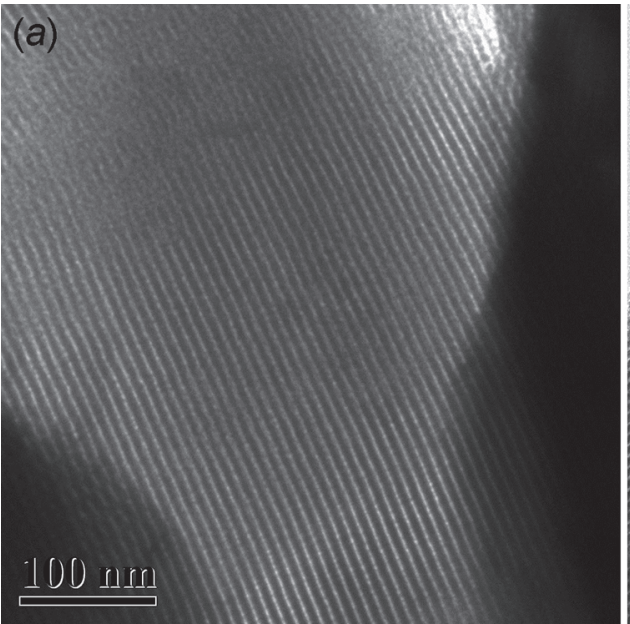

Fig. 4. TEM images of Fe-SBA-15: (a) Fe-SBA- $\mathrm{H}_{2} \mathrm{O}_{2}$ and (b) Fe-SBA.

sample $\left(\mathrm{Fe}-\mathrm{SBA}-\mathrm{H}_{2} \mathrm{O}_{2}\right)$, compared with calcined one $(\mathrm{Fe}-$ SBA). This is probably due to that the calcination process would lead to the easy oligomerization of iron species to iron clusters or iron oxides. Despite Fe-SBA has higher iron content (Table I), it also has much higher content of undesirable iron species, as compared with Fe-SBA- $\mathrm{H}_{2} \mathrm{O}_{2}$. Therefore, the $\mathrm{H}_{2} \mathrm{O}_{2}$-mediated template removal process is favorable to obtain well-isolated iron species.

Figure 2 displays the nitrogen sorption isotherms and BJH mesopore size distributions of Fe-SBA-15 samples. The corresponding textural properties are compiled in Table I. The isotherms can be classified as type IV with an H1 hysteresis loop, which is typical for mesoporous materials with large pores and a narrow pore size distribution. ${ }^{26}$ The well-defined step at relative high pressures of $0.6-0.8$ corresponds to the capillary condensation of nitrogen and indicates a narrow pore size distribution. The isotherms and narrow pore size distribution indicate that highly ordered Fe-SBA-15 samples are obtained. Compared with mild $\mathrm{H}_{2} \mathrm{O}_{2}$-treatment, the calcination lowers the BET surface area, pore volume and pore diameter, due to the structural shrinkage upon high-temperature calcination. Therefore, the template removal by liquid oxidation seems an efficient method to enhance the textural property substantially.

Figure 3 shows the XRD patterns of Fe-SBA-15. The successful formation of well-ordered mesoporous silicas with two-dimensional hexagonal structure is confirmed by the presence of a basal (100) peak along with (110) and (200) reflections in the low-angle region. ${ }^{26}$ No typical diffraction peaks due to iron oxide aggregates are observed in the high-angle diffraction range (not shown). It was well accepted that, the addition of inorganic salts is beneficial to the long range order of mesostructures, which can be attributed to the specific interaction between the nonionic surfactant and the metal ions. ${ }^{21,22,32-34}$ Both the nitrogen sorption and XRD demonstrate that, both the calcined and $\mathrm{H}_{2} \mathrm{O}_{2}$-treated samples have typical SBA-15 structures. From the TEM images of Fe-SBA-15 samples (Fig. 4), both

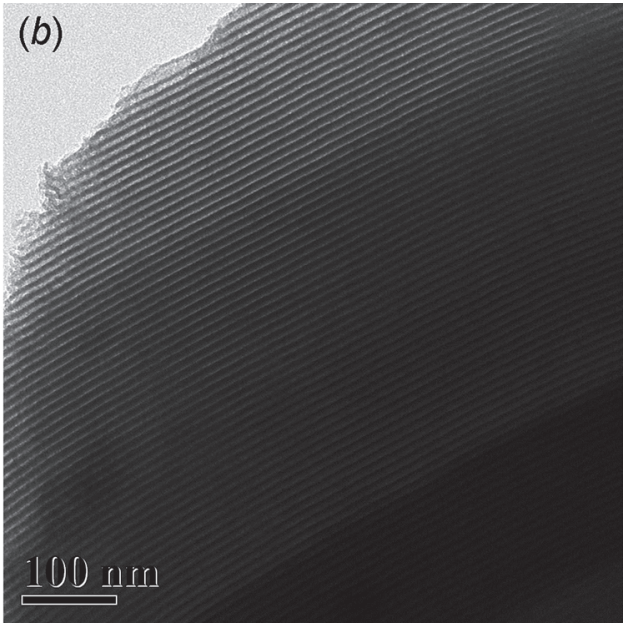

calcined and $\mathrm{H}_{2} \mathrm{O}_{2}$-treated samples show parallel cylindrical channel, indicating the formation of hexagonal mesoporous structure in the green synthesis procedure.

From the results above, Fe-SBA- $\mathrm{H}_{2} \mathrm{O}_{2}$, synthesized in a green process, is supposed to be an ordered mesoporous catalyst containing well-isolated iron species. The successful synthesis of Fe-SBA-15 can be attributed to the aid of $\mathrm{Fe}^{3+}$ and the weak acidity self-generated by the hydrolysis of $\mathrm{Fe}\left(\mathrm{NO}_{3}\right)_{3}$ in aqueous solution. ${ }^{21}$

\section{CONCLUSIONS}

In summary, a green synthesis procedure has been developed to prepare Fe-SBA-15 catalyst with highly ordered mesostructure. This synthesis system does not require adding external acid, and the template removal does not use calcination, which make the process much greener with less emission of liquid and gas pollutants. In addition, the $\mathrm{H}_{2} \mathrm{O}_{2}$ oxidation treatment may generate more desirable well-isolated iron sites and superior textural properties.

Acknowledgments: The authors are grateful to Professor Qihua Yang for the helpful discussion from Dalian Institute of Chemical Physics, Chinese Academy of Sciences. The project was sponsored by Key Laboratory of Oil and Gas Fine Chemicals, Ministry of Education and Xinjiang Uyghur Autonomous Region, Xinjiang University (XJDX0908-2012-5), "100 Talents" program of Chinese Academy of Sciences (Grant KJCX2-EW-H05), Qingdao Key Technology Program (Nos. 12-1-3-68-nsh, 13-1-3-123-nsh, 13-4-4-25-chg), and Doctoral Fund of Shandong Province (BS2013CL029).

\section{References and Notes}

1. Y. Wan and D. Y. Zhao, Chem. Rev. 107, 2821 (2007).

2. H. C. Xin, J. Zhao, S. T. Xu, J. P. Li, W. P. Zhang, X. W. Guo, E. J. M. Hensen, Q. H. Yang, and C. Li, J. Phys. Chem. C 114, 6553(2010). 
3. H. C. Xin, X. P. Li, Y. Fang, X. F. Yi, W. H. Hu, Y. Y. Chu, F. Zhang, A. M. Zheng, H. P. Zhang, and X. B. Li, J. Catal. 312, 204 (2014).

4. A. Taguchi and F. Schuth, Micropor. Mesopor. Mater. 77, 1 (2005).

5. Q. H. Yang, J. Liu, L. Zhang, and C. Li, J. Mater. Chem. 19, 1945 (2009).

6. C. Li, H. D. Zhang, D. M. Jiang, and Q. H. Yang, Chem. Commun. 43, 547 (2007).

7. Q. H. Yang, D. F. Han, H. Q. Yang, and C. Li, Chem. Asian J. 3, 1214 (2008).

8. H. C. Xin, X. P. Li, L. Chen, Y. Huang, G. R. Zhu, and X. B. Li, Energy Environ. Focus 2, 18 (2013).

9. A. Corma, Chem. Rev. 97, 2373 (1997).

10. H. C. Xin and Q. H. Yang, Petrochem. Technol. 35, 1017(2006).

11. A. J. J. Koekkoek, W. Kim, V. Degirmenci, H. Xin, R. Ryoo, and E. J. M. Hensen, J. Catal. 299, 81 (2013)

12. H. C. Xin, A. Koekkoek, Q. H. Yang, R. van Santen, C. Li, and E. J. M. Hensen, Chem. Commun. 45, 7590 (2009).

13. A. J. J. Koekkoek, H. Xin, Q. Yang, C. Li, and E. J. M. Hensen, Micropor. Mesopor. Mater. 145, 172 (2011).

14. C. Nozaki, C. G. Lugmair, A. T. Bell, and T. D. Tilley, J. Am. Chem. Soc. 124, 13194 (2002).

15. L. Chmielarz, P. Kustrowski, R. Dziembaj, P. Cool, and E. F. Vansant, Appl. Catal. B-Environ. 62, 369 (2006).

16. Y. Han, X. J. Meng, H. B. Guan, Y. Yu, L. Zhao, X. Z. Xu, X. Y. Yang, S. Wu, N. Li, and F. S. Xiao, Micropor. Mesopor. Mater. 57, $\frac{191}{\text { A. (2003). }}$.

17. A. Tuel, I. Arcon, and J. M. M. Millet, J. Chem. Soc.-Faraday Trans. 94, 3501 (1998).

18. Z. Y. Yuan, S. Q. Liu, T. H. Chen, J. Z. Wang, and H. X. Li, J. Chem. Soc.-Chem. Commun. 31, 973 (1995).
19. H. C. Xin, J. Liu, F. T. Fan, Z. C. Feng, G. Q. Jia, Q. H. Yang, and C. Li, Micropor. Mesopor. Mater. 113, 231 (2008).

20. H. C. Xin, J. T. Tang, F. T. Fan, Q. H. Yang, and C. Li, J. Inorg. Mater. 25, 107 (2010).

21. H. C. Xin, J. Zhao, X. B. Li, J. T. Tang, and Q. H. Yang, Micropor. Mesopor. Mater. 190, 54 (2014).

22. Y. Li, Z. C. Feng, H. C. Xin, F. T. Fan, J. Zhang, P. Magusin, E. J. M. Hensen, R. A. van Santen, Q. H. Yang, and C. Li, J. Phys. Chem. $B$ 110, 26114 (2006)

23. Y. Li, H. A. Xia, F. T. Fan, Z. C. Feng, R. A. Van Santen, E. J. M. Hensen, and C. Li, Chem. Commun. 44, 774 (2008).

24. S. Rostamnia and H. Xin, Appl. Organometal. Chem. 27, 348 (2013).

25. S. Rostamnia, H. Xin, X. Liu, and K. Lamei, J. Mol. Catal. A-Chem. 374, 85 (2013).

26. D. Y. Zhao, Q. S. Huo, J. L. Feng, B. F. Chmelka, and G. D. Stucky, J. Am. Chem. Soc. 120, 6024(1998).

27. S. Y. Chen, L. Y. Jang, and S. F. Cheng, Chem. Mater. 16, 4174 (2004).

28. S. Y. Chen, H. D. Tsai, W. T. Chuang, J. J. Lee, C. Y. Tang, C. Y. Lin, and S. Cheng, J. Phys. Chem. C 113, 15226 (2009).

29. Y. M. Liu, J. Xu, L. He, Y. Cao, H. Y. He, D. Y. Zhao, J. H. Zhuang, and K. N. Fan, J. Phys. Chem. C 112, 16575 (2008).

30. B. R. Jermy, S. Y. Kim, K. V. Bineesh, M. Selvaraj, and D. W. Park, Micropor. Mesopor. Mater. 121103 (2009).

31. A. Vinu, T. Krithiga, V. Murugesan, and M. Hartmann, Adv. Mater. 16, 1817 (2004).

32. J. T. Tang, J. Liu, P. Y. Wang, H. Zhong, and Q. H. Yang, Micropor. Mesopor. Mater. 127, 119 (2010).

33. L. Zhang, Q. H. Yang, W. H. Zhang, Y. Li, J. Yang, D. M. Jiang, G. R. Zhu, and C. Li, J. Mater. Chem. 15, 2562 (2005).

34. J. T. Tang, H. C. Xin, W. G. Su, J. Liu, C. Li, and Q. H. Yang, Chinese J. Catal. 31, 386 (2010). 